\title{
Challenging Regional Psoriasis and Ustekinumab Biotherapy: Impact of the Patterns of Disease
}

\author{
Trinh Hermanns-Lê,, ${ }^{1}$ Enzo Berardesca, ${ }^{2}$ Gérald E. Piérard, \\ Marianne Lesuisse, ${ }^{3}$ and Claudine Piérard-Franchimont ${ }^{1,4}$ \\ ${ }^{1}$ Department of Dermatopathology, University Hospital of Liège, 4000 Liège, Belgium \\ ${ }^{2}$ San Gallicano Dermatological Institute, 00144 Roma, Italy \\ ${ }^{3}$ Department of Dermatology, Regional Hospital Citadelle, 4000 Liège, Belgium \\ ${ }^{4}$ Department of Dermatology, Regional Hospital of Huy, 4500 Huy, Belgium
}

Correspondence should be addressed to Gérald E. Piérard, gerald.pierard@ulg.ac.be

Received 30 April 2012; Accepted 1 August 2012

Academic Editor: Philippe Humbert

Copyright (๑) 2012 Trinh Hermanns-Lê et al. This is an open access article distributed under the Creative Commons Attribution License, which permits unrestricted use, distribution, and reproduction in any medium, provided the original work is properly cited.

In some patients, psoriasis appears refractory to many treatments, particularly when the disease is confined to some specific body regions. In this respect, palmoplantar psoriasis and palmoplantar pustulosis are possibly related conditions in their immunopathomechanisms involving Il-12, IL-23, and Th17. Nail psoriasis and scalp psoriasis are two other particular psoriasis manifestations. Accordingly, ustekinumab was tested in a few of these patients. The present paper is limited to peer-reviewed case reports. Data were not supported by bioinstrumental assessments and controlled trials. Overall, they are indicative of potential efficacy. The cost-effectiveness and the risk-benefit assessments merit further investigations.

\section{Introduction}

Psoriasis is a common skin disorder of major economic burden that is associated with a series of comorbidities [1]. It affects approximately $2 \%$ of Caucasians at some stage during their life. The typical lesions of psoriasis are raised erythematous scaly plaques whose edges are sharply marginated. Lesions tend to be circular or oval, but occasionally exhibit circinate and geographic outlines. A number of factors precipitate or aggravate psoriasis. Nowadays, there is agreement in the scientific community about the autoimmune origin of psoriasis. Both genetic and environmental influences play a critical role.

The disease develops on any part of the skin, but it predominates on the knees, elbows, sacral region, and the retroauricular area. In some patients, psoriasis is restricted to or particularly active at some other specific body sites $[2,3]$. Such regional psoriasis types frequently represent a challenging and disabling chronic condition. It is commonly refractory to many conventional topical treatments. The origin of the peculiar distribution of psoriatic lesions in a given patient often remains unsettled. However, most regional psoriasis types likely result from the impact of local exogenous triggers. They should be searched for and identified in order to adequately manage the skin condition. Indeed, the anatomic and physiopathologic features of the skin differ from one part of the body to another.

Ustekinumab is a fully human IgG1 K-kappa monoclonal antibody inhibiting the $\mathrm{p} 40$ subunit shared by interleukin (IL)-12 and IL-23 [4-6]. The resulting reduction in IL$17 \mathrm{~A}$ and IL-17F abates the production of T-helper 17 cells $[6,7]$. In addition, tissue recruitment of neutrophils is abated [8-11]. Ustekinumab is approved for the treatment of moderate-to-severe psoriasis $[12,13]$. For sure, the information about the effect of ustekinumab on regional psoriasis does not meet the requirements of evidence-based medicine. Currently, there are no specific controlled studies focused on these peculiar forms of psoriasis. However, the available information enters the concept of patient-centered medicine (PCM). The method consists of applying to individual patients the advances from related studies performed on populations. In addition, PCM collects information from the 
patient and assesses both the alteration and improvement of the quality of life (QoL). In localized types of psoriasis, the aim of treatment is more oriented toward QoL improvement than to blanching an extensive body surface involvement. QoL is an important feature in this field of pathology because, for similar body surface involvement, regional psoriasis is probably more disturbing for the patient than lesions on covered parts of the body. In addition, the impact of the pattern of disease probably influences the drug efficacy.

This paper reviews the peer-reviewed literature about difficult-to-treat localized forms of psoriasis ultimately treated with ustekinumab.

\section{Palmoplantar Psoriasis}

Palmoplantar involvement is a typical psoriatic location. Lesions are characterized by diffuse erythema, infiltration, fissuring, hyperkeratosis, and recurrent crops of sterile pustules. More exactly, two different appearances of psoriasis are recognized on the palms and soles. Firstly, one presentation combines thick scaly areas with moderate erythema. The distinction is occasionally difficult to distinguish from chronic contact dermatitis. Secondly, the disease evokes pustular psoriasis characterized by the presence of small sterile pustules dispersed on a discrete scaly erythematous area of the palms and soles. The disorder is rarely associated with typical psoriatic plaques on the trunk and limbs.

Palmoplantar psoriasis is frequently painful and affects daily activities. An isomorphic phenomenon likely maintains the pathologic process active. Palmoplantar pustulosis is another clinical entity possibly representing a variant of psoriasis. In general, therapy is similarly disappointing for these two conditions, and therapeutic standards have not yet been established so far $[14,15]$.

Recently, ustekinumab administered at a dose recommended for plaque type psoriasis showed efficacy in the treatment of a series of patients with palmoplantar psoriasis and palmoplantar pustulosis [16-20]. About one-third of the patients achieved clinical clearance after 16 weeks of ustekinumab treatment [20]. In addition, some improvement was noticed in most of the other patients. Occasionally, the response rate to ustekinumab therapy was slower than that commonly reported for plaque psoriasis. In palmoplantar psoriasis, ustekinumab therapy was well tolerated without any reported adverse effects. However, a single case report pointed to a paradoxical effect where palmoplantar psoriasis was exacerbated following ustekinumab treatment [21].

\section{Nail Psoriasis}

Psoriasis as well as a few other chronic skin diseases is responsible for concurrent onychopathies. Nail changes are common in the severe forms of psoriasis. Globally, up to $40-60 \%$ of psoriatic patients suffer from nail involvement [22-26]. The nail changes are commonly predictive of arthropathies $[27,28]$. The latter condition encompasses distinct pattern of enthesitis, osteitis, and synovitis. Psoriatic patients with onychopathy are almost threefold more likely to develop arthropathies than patients without nail involvement [29]. The lifetime incidence of psoriatic onychopathies reaches $80-90 \%$ [30]. However, milder nail involvements frequently remain overlooked by physicians despite the burden experienced by the patients. Clinical data and guidelines for managing nail onychopathy are scanty $[26,31]$.

Occasionally, psoriasis affects only the nails without any other skin involvement $[24,26]$. In these circumstances, the diagnosis is difficult to establish and particularly the distinction with some onychomycosis. In order to try to establish the diagnosis, a nail specimen should be taken for histomycology and conventional histopathology [32,33].

The normal nail plate is hard but flexible, and it grows continuously. It is frequently subject to a number of microtraumatisms. A healthy nail plate grossly looks smooth, but close examination reveals discrete unevenness. The specific surface microrelief has physiopathologic implications. At close inspection, an uneven relief is possibly visible in children. In middle-aged individuals, the physiologic changes often remain too discrete to be readily discernable. By contrast, it becomes noticeable at the naked eye examination in a number of elderly people.

The most characteristic features of psoriatic onychopathy are oil drops, onycholysis, and nail plate pitting. Other common clinical features of nail psoriasis are pitting, leukonychia, red spots in the lunula, nail plate crumbling, oil drop, onycholysis, nail bed hyperkeratosis, and splinter hemorrhage. Extensive involvement of the matrix results in trachyonychia. These aspects are frequent in patients with severe psoriasis $[30,34,35]$. However, there is typically a difference in prevalence of each aspect between fingernails and toenails [22]. Nail psoriasis evolves independently from skin psoriasis. The ungual lesions apparently benefit from treatments using ustekinumab [36-41] and other biotherapies as well [42-49]. Of note, many of the trials on psoriatic onychopathies using biologics need to be considered as preliminary because of the lack of controls to reduce bias (open-label, unblinded design) and interindividual variability (lack of a control group). However, a large double-blind, placebo-controlled trial on ustekinumab was conducted in 545 psoriatic patients with nail involvement [36]. A 25\% NAPSI improvement was present at week 12 compared to a complete lack of effect in the placebo group. Nail psoriasis continued to improve in patients in all groups treated with ustekinumab over time after the placebo-controlled portion of the study, and improvements were sustained through 1 year.

The descriptive nail psoriasis severity index (NAPSI) is conveniently used for rating therapeutic effects $[25,28,30$, $50,51]$. NAPSI was claimed to be reproducible and easy to perform. For that purpose, each nail is divided into four quadrants to be assessed for the presence of any psoriatic change originating from both the nail matrix (pitting, leukonychia, and nail plate crumbling) and the nail bed (oil drop discoloration, onycholysis, hyperkeratosis, and splinter hemorrhages). If any sign is present in all four quadrants, the nail is given a score of 4 to a score of 0 in absence of alteration in any quadrant. Each nail is assigned both a nail matrix and a nail bed score of $0-4$, which are combined to yield a total 
score of $0-8$ for each nail. All nails are assessed with the total NAPSI score corresponding to the sum of the scores, reaching up to 80 if only the 10 fingernails are considered or up to 160 if toenails are included. In practice, it is possible to target one specific nail for assessing drug effects. Other scoring systems for nail psoriasis were offered [52] including the nail psoriasis quality of life scale (NPQ10) [53].

Objective assessments of the nail changes are relevant for both research and routine clinical use. They rely on noninvasive optical profilometry allowing the assessment of onychochronobiology [54-56]. Other clinical outcome measures in nail psoriasis are scanty [25]. The examination of negative silicone replicas of the nail microrelief is a convenient procedure. The procedure is achieved using one of several methods including mechanical profilometry, autofocus laser beam profilometry, oblique illumination of the replicas, and optical measurement of the translucent replica thickness. Optical profilometry relies on standardized parameters related to the nail surface harshness. In addition, due to the sustained nail growth, onychochronobiology is explored using the same means at different time intervals. This procedure clearly highlights the effects of therapies [57]. Optical coherence tomography can be applied to psoriatic onychopathy [58]. Nonetheless, the objective quantitative assessments of nail improvement under ustekinumab therapy have not yet been reported.

\section{Scalp Psoriasis}

Psoriasis possibly affects the scalp by two ways, namely, psoriatic alopecia without any scaliness and regular scalp psoriasis with typical epidermal involvement.

The hair cycle encompasses three main successive phases, namely, the anagen, catagen, and telogen phases. The cycle ends with hair shedding during teloptosis or exogen phase $[59,60]$. Any prolonged lag phase between two successive hair cycles corresponds to the "eclipse phenomenon" $[61,62]$. These key events are of particular importance when considering hair fullness in psoriatic patients and the effects of treatments [63].

Some alterations occasionally occur in the hair cycle of psoriatic patients. These changes consist of a telogen effluvium characterized by an early passage in teloptosis contributing to a relative synchronization of the hair cycle and to the hair eclipse phenomenon [63]. The psoriatic telogen effluvium possibly accompanies manifestations of psoriasis comorbidities [1]. Conversely, the length of the anagen phase is extended at the site of some psoriatic lesions. In addition, the hair structure is possibly affected by psoriasis $[64,65]$. All these features are conveniently explored using the trichogram method which is minimally invasive, cheap, and rapid. No data are yet reported about the effect of ustekinumab on psoriatic effluvium.

Clinical involvement of the scalp is a common manifestation of psoriasis, occurring in up to $80 \%$ of patients. It represents a challenging psoriatic type to treat. Psoriasis localized to the scalp was reported to be rapidly controlled ( 8 weeks) by ustekinumab treatment [66] and other biologics as well $[45,67,68]$. At present, the information about the ustekinumab effect on scalp psoriasis remains scanty. Controlled studies are warranted.

\section{Conclusion}

The extent of psoriatic lesions is highly variable among patients although in most cases it remains limited to less than $10 \%$ of the total skin area. Psoriasis frequently involves specific sites including hands, nails, and scalp where it causes great distress. Approximately $15 \%$ of all cases exhibit peculiar clinical patterns. The disease is chronic and potentially lifelong. Current evidence indicates a key involvement of the immune system (innate and acquired) in the disease pathogenesis. This has conducted to a rapid advance in immunotherapy for the disease.

The number of ustekinumab-treated patients with palmoplantar psoriasis and nail and scalp involvement remains yet too limited to allow drawing definite conclusions. At present, biotherapies including ustekinumab are regarded as a second-line treatment for patients with challenging regional psoriasis not responding to conventional management $[17,67,68]$. Anyway, the cost-effectiveness ratio is important to consider and any potential adverse event to ustekinumab should be considered with caution [69].

The origin of the specific regional localizations of psoriasis remains a puzzling feature. The reasons remain purely speculative. Among them, an isomorphic reaction following repeat microtraumatisms is probably involved. It is possible that a cluster of stimulated Th17 cells have a restricted homing capacity to specific body regions. The specific structure of the regional skin tissue is likely another factor involved in the process. Anyway, the information presently available suggests that ustekinumab is equally effective on the regional psoriatic lesions as on other difficultto-treat psoriatic plaques.

No treatments are curative for psoriasis. Instead, the gold standard of care is to palliate the disease safely and effectively in the long term. Treatment depends on many key variables including the disease extent, the type of psoriasis, the patient expectations, and the concomitant comorbidities. Thus, treatment has to be individualized. Multiple strategies are possible based on clinical need and include sequential therapy, rotational therapy, and combination therapy.

Therapeutic options are broadly divided into three areas, namely, topical therapy, phototherapy, and systemic therapy. Topical therapies, including vitamin D analogues, corticosteroids, and anthralin, are usually the first option particularly when the disease is localized. Phototherapy (UVB and PUVA), although effective in most patients, presents a logistic problem for many patients (regular hospital visits for at least 6 weeks) and has to be limited because of the risk of inducing skin cancers. Standard systemic drugs, such as acitretin, methotrexate, cyclosporine $\mathrm{A}$, and fumaric acid esters, are commonly reserved for patients with moderateto-severe disease. Usage has to be limited in duration and dosage, depending on the individual toxicity of the various agents. There are many patients in whom these drugs are 
inadequately effective, poorly tolerated, produce toxicity, or in whom they are contraindicated. A minority of patients at times require inpatient hospital management. Indications for inpatient management include, severe disease of rapid onset, need for intense topical and phototherapy, and initiation of systemic therapy in refractory cases. There is now a raft of new biotherapies targeting the immune system and holding much promise in the treatment of stubborn psoriasis.

Tackling back regional psoriasis and any of its impact on the psychology of well-being have to be considered in the light of new biotherapies. Interdrug comparisons are difficult to perform in the present conditions due to their rarity and to the process of patient-based medicine which is modulated on an individual basis. Globally, ustekinumab appears effective both in biologic-naive patients as well as when other biotherapies have previously failed [70]. It is expected that the response to ustekinumab will be higher in patients weighing less than $100 \mathrm{~kg}$ [70].

\section{Conflict of Interests}

The authors declare that there is no conflict of interests.

\section{References}

[1] G. E. Piérard, C. Piérard-Franchimont, G. Szepetiuk, P. Paquet, and P. Quatresooz, "The therapeutic potential of TNF$\alpha$ antagonists for skin psoriasis comorbidities," Expert Opinion on Biological Therapy, vol. 10, no. 8, pp. 1197-1208, 2010.

[2] K. Kragballe, "Management of difficult to treat locations of psoriasis: scalp, face, flexures, palm/soles and nails," Current Problems in Dermatology, vol. 38, pp. 160-171, 2009.

[3] D. McGonagle, N. Palmou Fontana, A. L. Tan, and M. Benjamin, "Nailing down the genetic and immunological basis for psoriatic disease," Dermatology, vol. 221, supplement 1, pp. S15-S22, 2010.

[4] C. E. M. Griffiths, "Comparing biological therapies in psoriasis: implications for clinical practice," Journal of the European Academy of Dermatology and Venereology, vol. 24, supplement 6, pp. S10-S14, 2010.

[5] J. C. Prinz, "From bench to bedside-translational research in psoriasis," Journal of the European Academy of Dermatology and Venereology, vol. 24, supplement 6, pp. S1-S4, 2010.

[6] P. Quatresooz, T. Hermanns-Lê, G. E. Piérard, P. Humbert, P. Delvenne, and C. Piérard-Franchimont, "Ustekinumab in psoriasis immunopathology with emphasis on the Th17-IL23 axis. A primer," Journal of Biomedicine and Biotechnology, vol. 2012, Article ID 147413, 5 pages, 2012.

[7] A. Di Cesare, P. Di Meglio, and F. O. Nestle, "The IL23 Th17 axis in the immunopathogenesis of psoriasis," Journal of Investigative Dermatology, vol. 129, no. 6, pp. 1339-1350, 2009.

[8] J. Witowski, K. Ksiazek, and A. Jörres, "Interleukin-17: a mediator of inflammatory responses," Cellular and Molecular Life Sciences, vol. 61, no. 5, pp. 567-579, 2004.

[9] H. Watanabe, M. Kawaguchi, S. Fujishima et al., "Functional characterization of IL-17F as a selective neutrophil attractant in psoriasis," Journal of Investigative Dermatology, vol. 129, no. 3, pp. 650-656, 2009.
[10] M. Pelletier, L. Maggi, A. Micheletti et al., "Evidence for a cross-talk between human neutrophils and Th17 cells," Blood, vol. 115, no. 2, pp. 335-343, 2010.

[11] L. Roussel, F. Houle, C. Chan et al., "IL-17 promotes p38 MAPK-dependent endothelial activation enhancing neutrophil recruitment to sites of inflammation," Journal of Immunology, vol. 184, no. 8, pp. 4531-4537, 2010.

[12] C. L. Leonardi, A. B. Kimball, K. A. Papp et al., "Efficacy and safety of ustekinumab, a human interleukin-12/23 monoclonal antibody, in patients with psoriasis: 76-week results from a randomised, double-blind, placebo-controlled trial (PHOENIX 1)," The Lancet, vol. 371, no. 9625, pp. 1665-1674, 2008.

[13] E. Daudén, D. Santiago-Et-Sánchez-Mateos, E. SotomayorLópez, and A. García-Díez, "Ustekinumab: effective in a patient with severe recalcitrant generalized pustular psoriasis," British Journal of Dermatology, vol. 163, no. 6, pp. 1346-1347, 2010.

[14] A. A. Pettey, R. Balkrishnan, S. R. Rapp, A. B. Fleischer, and S. R. Feldman, "Patients with palmoplantar psoriasis have more physical disability and discomfort than patients with other forms of psoriasis: implications for clinical practice," Journal of the American Academy of Dermatology, vol. 49, no. 2, pp. 271-275, 2003.

[15] A. M. Marsland, R. J. Chalmers, S. Hollis, J. Leonardi-Bee, and C. E. Griffiths, "Interventions for chronic palmoplantar pustulosis," Cochrane Database of Systematic Reviews, vol. 1, Article ID CD001433, 2006.

[16] C. B. Livideanu, M. Lahfa, J. Mazereeuw-Hautier, and C. Paul, "Efficacy of ustekinumab in palmoplantar psoriasis," Dermatology, vol. 221, no. 4, pp. 321-323, 2010.

[17] S. Gerdes, J. Franke, S. Domm, and U. Mrowietz, "Ustekinumab in the treatment of palmoplantar pustulosis," British Journal of Dermatology, vol. 163, no. 5, pp. 1116-1118, 2010.

[18] A. Nuno-Gonzalez, E. Gomez de la Fuente, F. J. VicenteMartin, and J. L. Lopez-Estebaranz, "Good response of hyperkeratotic palmoplantar psoriasis to ustekinumab," Actas Dermosifiliografia, vol. 103, pp. 169-170, 2012.

[19] B. de Unamuno-Bustos, R. Balester-Sanchez, V. OliverMartinez, and V. Alegre de Miquel, "Ustekinumab for the treatment of palmar-plantar pustulosis," Actas Dermosifiliografia, vol. 102, pp. 833-835, 2011.

[20] S. C. Au, A. M. Goldminz, N. Kim et al., "Investigatorinitiated, open-label trial of ustekinumab for the treatment of moderate to severe palmoplantar psoriasis," Journal of Dermatological Treatment. In press.

[21] G. Safa, A. Martin, and L. Darrieux, "Exacerbation of infliximab-induced palmoplantar psoriasis under ustekinumab therapy in a patient with ankylosing spondylitis," Journal of Clinical Rheumatology, vol. 17, pp. 385-386, 2011.

[22] A. Kyriakou, A. Patsatsi, and D. Sotiriadis, "Detailed analysis of specific nail psoriasis features and their correlations with clinical parameters: a cross-sectional study," Dermatology, vol. 223, pp. 222-229, 2011.

[23] C. Grover, B. S. Reddy, and C. K. Uma, "Diagnosis of nail psoriasis: importance of biopsy and histopathology," British Journal of Dermatology, vol. 153, no. 6, pp. 1153-1158, 2005.

[24] M. M. Jiaravuthisan, D. Sasseville, R. B. Vender, F. Murphy, and C. Y. Muhn, "Psoriasis of the nail: anatomy, pathology, clinical presentation, and a review of the literature on therapy," Journal of the American Academy of Dermatology, vol. 57, no. 1, pp. 1-27, 2007. 
[25] M. Augustin and A. Ogilvie, "Methods of outcomes measurement in nail psoriasis," Dermatology, vol. 221, supplement 1 , pp. 23-28, 2010.

[26] R. G. Langley and E. Daudén, "Treatment and management of psoriasis with nail involvement: a focus on biologic therapy," Dermatology, vol. 221, supplement 1, pp. 29-42, 2010.

[27] L. Williamson, N. Dalbeth, J. L. Dockerty, B. C. Gee, R. Weatherall, and B. P. Wordsworth, "Extended report: nail disease in psoriatic arthritis_clinically important, potentially treatable and often overlooked," Rheumatology, vol. 43, no. 6, pp. 790-794, 2004.

[28] D. de Berker, "Management of psoriatic nail disease," Seminars in Cutaneous Medicine and Surgery, vol. 28, no. 1, pp. 39-43, 2009.

[29] F. C. Wilson, M. Icen, C. S. Crowson, M. T. McEvoy, S. E. Gabriel, and H. M. Kremers, "Incidence and clinical predictors of psoriatic arthritis in patients with psoriasis: a populationbased study," Arthritis and Rheumatism, vol. 61, no. 2, pp. 233239, 2009.

[30] M. M. Jiaravuthisan, D. Sasseville, R. B. Vender, F. Murphy, and C. Y. Muhn, "Psoriasis of the nail: anatomy, pathology, clinical presentation, and a review of the literature on therapy," Journal of the American Academy of Dermatology, vol. 57, no. 1, pp. 1-27, 2007.

[31] R. G. Langley, J. H. Saurat, and K. Reich, "Recommendations for the treatment of nail psoriasis in patients with moderate to severe psoriasis: a dermatology expert group consensus," Journal of the European Academy of Dermatology and Venereology, vol. 26, pp. 373-381, 2012.

[32] G. E. Piérard, "Spores, sporodochia and fomites in onychomycosis," Dermatology, vol. 213, no. 2, pp. 169-172, 2006.

[33] G. E. Piérard, P. Quatresooz, and J. E. Arrese, "Spotlight on nail histomycology," Dermatologic Clinics, vol. 24, no. 3, pp. 371-374, 2006.

[34] E. M. de Jong, B. A. Seegers, M. K. Gulinck, J. B. Boezeman, and P. C. van de Kerkhof, "Psoriasis of the nails associated with disability in a large number of patients: results of a recent interview with 1,728 patients," Dermatology, vol. 193, no. 4, pp. 300-303, 1996.

[35] D. McGonagle, A. L. Tan, and M. Benjamin, "The nail as a musculoskeletal appendage-implications for an improved understanding of the link between psoriasis and arthritis," Dermatology, vol. 218, no. 2, pp. 97-102, 2009.

[36] P. Rich, C. Guzzo, Y. Wang, and K. Gordon, "Improvement in nail psoriasis with ustekinumab, a new anti-IL-12/23p40 monoclonal antibody: results from a phase 3 trial," American Academy of Dermatology, Annual Meeting, 2008.

[37] P. Rich, R. Langley, C. Guzzo et al., "Improvement in nail psoriasis with ustekinumab, a new anti-IL-12/23p40 monoclonal antibody: results from a pahse 3 trial (poster FP107)," 17th Congress EADV, Paris, France, 2008.

[38] E. Rallis, S. Kintzoglou, and C. Verros, "Ustekinumab for rapid treatment of nail psoriasis," Archives of Dermatology, vol. 146, no. 11, pp. 1315-1316, 2010.

[39] A. Patsatsi, A. Kyriakou, and D. Sotiradis, "Ustekinumab in nail psoriasis : an open-label, uncontrolled, nonrandomized study," Journal of Dermatological Treatment. In press.

[40] D. Rigopoulos, S. Gregoriou, M. Makris, and D. Ioannides, "Efficacy of ustekinumab in nail psoriasis and improvement in nail-associated quality of life in a population treated with ustekinumab for cutaneous psoriasis : an open prospective unblinded study," Dermatology, vol. 223, pp. 325-329, 2011.

[41] L. Bianchi, A. Bergamin, C. de Felice, E. Capriotti, and S. Chimenti, "Remission and time of resolution of nail psoriasis during infliximab therapy," Journal of the American Academy of Dermatology, vol. 52, no. 4, pp. 736-737, 2005.

[42] M. Lawry, "Biological therapy and nail psoriasis," Dermatology and Therapy, vol. 20, no. 1, pp. 60-67, 2007.

[43] F. van den Bosch, R. Reece, and F. Behrens, "Clinically important nail psoriasis improvements are achieved with adalimumab (Humira): results from a large open-label prospective study (STEREO)," Annals of Rheumatic Diseases, vol. 66, supplement 2, p. 421, 2007.

[44] P. Rich, C. E. Griffiths, K. Reich et al., "Baseline nail disease in patients with moderate to severe psoriasis and response to treatment with infliximab during 1 year," Journal of the American Academy of Dermatology, vol. 58, no. 2, pp. 224-231, 2008.

[45] D. Rigopoulos, S. Gregoriou, A. Stratigos et al., "Evaluation of the efficacy and safety of infliximab on psoriatic nails: an unblinded, nonrandomized, open-label study," British Journal of Dermatology, vol. 159, no. 2, pp. 453-456, 2008.

[46] K. Kragballe, "Management of difficult to treat locations of psoriasis: scalp, face, flexures, palm/soles and nails," Current Problems in Dermatology, vol. 38, pp. 160-171, 2009.

[47] K. Reich, "Approach to managing patients with nail psoriasis," Journal of the European Academy of Dermatology and Venereology, vol. 23, supplement 1, pp. 15-21, 2009.

[48] R. G. Langley and E. Daudén, "Treatment and management of psoriasis with nail involvement: a focus on biologic therapy," Dermatology, vol. 221, supplement 1, pp. 29-42, 2010.

[49] D. Rigopoulos, S. Gregoriou, E. Lazaridou et al., "Treatment of nail psoriasis with adalimumab: an open label unblinded study," Journal of the European Academy of Dermatology and Venereology, vol. 24, no. 5, pp. 530-534, 2010.

[50] D. de Berker, "Management of nail psoriasis," Clinical and Experimental Dermatology, vol. 25, no. 5, pp. 357-362, 2000.

[51] R. L. Baran, "A nail psoriasis severity index," British Journal of Dermatology, vol. 150, no. 3, pp. 568-569, 2004.

[52] S. P. Cannavò, F. Guarneri, M. Vaccaro, F. Borgia, and B. Guarneri, "Treatment of psoriatic nails with topical cyclosporin: a prospective, randomized placebo-controlled study," Dermatology, vol. 206, no. 2, pp. 153-156, 2003.

[53] J. P. Ortonne, R. Baran, M. Corvest, C. Schmitt, J. J. Voisard, and C. Taieb, "Development and validation of nail psoriasis quality of life scale (NPQ10)," Journal of the European Academy of Dermatology and Venereology, vol. 24, no. 1, pp. 22-27, 2010.

[54] N. Nikkels-Tassoudji, C. Pierard-Franchimont, P. De Doncker, and G. E. Pierard, "Optical profilometry of nail dystrophies," Dermatology, vol. 190, no. 4, pp. 301-304, 1995.

[55] G. E. Piérard and C. Piérard-Franchimont, "Dynamics of psoriatic trachyonychia during low-dose cyclosporin A treatment: a pilot study on onychochronobiology using optical profilometry," Dermatology, vol. 192, no. 2, pp. 116-119, 1996.

[56] C. Piérard-Franchimont and G. E. Piérard, "Surface image analysis of nail alterations in juvenile pityriasis rubra pilaris," Skin Research and Technology, vol. 4, no. 1, pp. 34-36, 1998.

[57] G. E. Piérard, M. Caucanas, and C. Piérard-Franchimont, "Nail surface topography and onychochronobiology," in Noninvasive diagnostic techniques in clinical dermatology, E. Berardesca, K. P. Wilhelm, and H. I. Maibach, Eds., Springer, Berlin, Germany, 2012.

[58] S. Z. Aydin, Z. Ash, F. Del Galdo et al., "Optical coherence tomography: a new tool to assess nail disease in psoriasis?" Dermatology, vol. 222, pp. 311-313, 2011.

[59] K. S. Stenn and R. Paus, "Controls of hair follicle cycling," Physiological Reviews, vol. 81, no. 1, pp. 449-494, 2001. 
[60] C. Piérard-Franchimont and G. E. Piérard, "Teloptosis, a turning point in hair shedding biorhythms," Dermatology, vol. 203, no. 2, pp. 115-117, 2001.

[61] M. Courtois, G. Loussouarn, C. Hourseau, and J. F. Grollier, "Hair cycle and alopecia," Skin Pharmacology, vol. 7, no. 1-2, pp. 84-89, 1994.

[62] C. Piérard-Franchimont, L. Petit, G. Loussouarn, D. SaintLéger, and G. E. Piérard, "The hair eclipse phenomenon: sharpening the focus on the hair cycle chronobiology," International Journal of Cosmetic Science, vol. 25, no. 6, pp. 295-299, 2003.

[63] G. E. Piérard, C. Piérard-Franchimont, R. Marks, P. Elsner, and The EEMCO Group, "EEMCO guidance for the assessment of hair shedding and alopecia," Skin Pharmacology and Physiology, vol. 17, no. 2, pp. 98-110, 2004.

[64] K. S. Kim, M. K. Shin, J. J. Ahn, C. R. Haw, and H. K. Park, "A comparative study of hair shafts in scalp psoriasis and seborrheic dermatitis using atomic forcemicroscopy," Skin Research and Technology. In press.

[65] M. K. Shin, K. S. Kim, J. J. Ahn, N. I. Kim, H. K. Park, and C. R. Haw, "Investigation of the hair of patients with scalp psoriasis using atomic force microscopy," Clinical and Experimental Dermatology, vol. 37, pp. 156-163, 2012.

[66] A. Di Cesare, M. C. Fargnoli, and K. Peris, "Rapid response of scalp psoriasis to ustekinumab," European Journal of Dermatology, vol. 21, pp. 993-994, 2011.

[67] C. S. Chan, A. S. Van Voorhees, M. G. Lebwohl et al., "Treatment of severe scalp psoriasis: from the Medical Board of the National Psoriasis Foundation," Journal of the American Academy of Dermatology, vol. 60, no. 6, pp. 962-971, 2009.

[68] J. Bagel, C. Lynde, S. Tyring, G. Kricorian, Y. Shi, and P. Klekotka, "Moderate to severe plaque psoriasis with scalp involvement: a randomized, double-blind, placebo-controlled study of etanercept," Journal of the American Academy of Dermatology, vol. 67, pp. 86-92, 2012.

[69] C. L. Leonardi, A. B. Kimball, K. A. Papp et al., "Efficacy and safety of ustekinumab, a human interleukin-12/23 monoclonal antibody, in patients with psoriasis: 76-week results from a randomised, double-blind, placebo-controlled trial (PHOENIX 1)," The Lancet, vol. 371, no. 9625, pp. 1665-1674, 2008.

[70] V. Ruiz Salas, L. Puig, and A. Alomar, "Ustekinumab in clinical practice: response depends on dose and previous treatment," Journal of the European Academy of Dermatology and Venereology, vol. 26, pp. 506-513, 2012. 


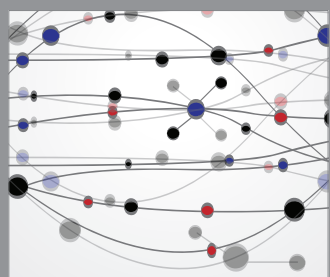

The Scientific World Journal
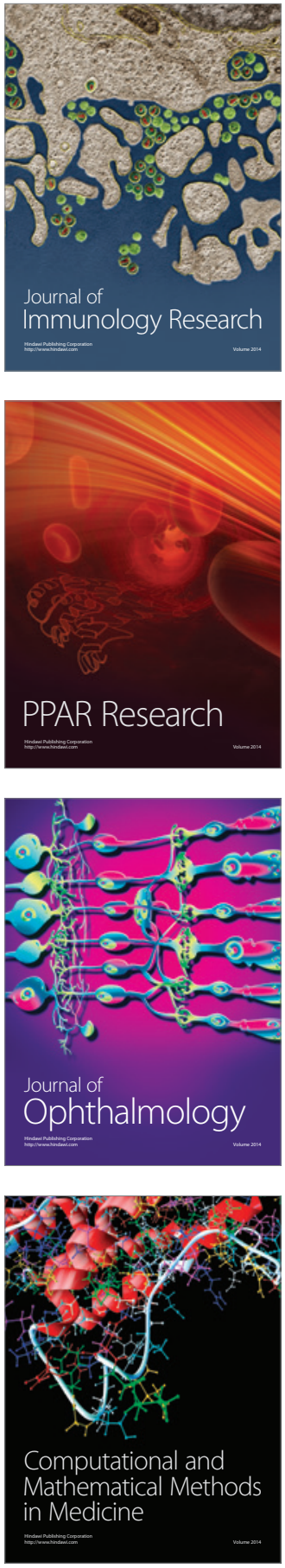

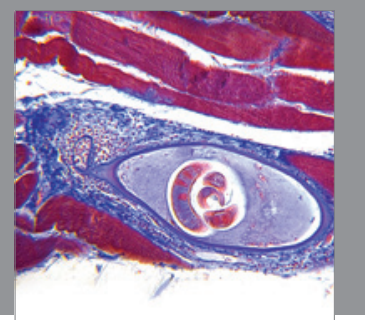

Gastroenterology

Research and Practice
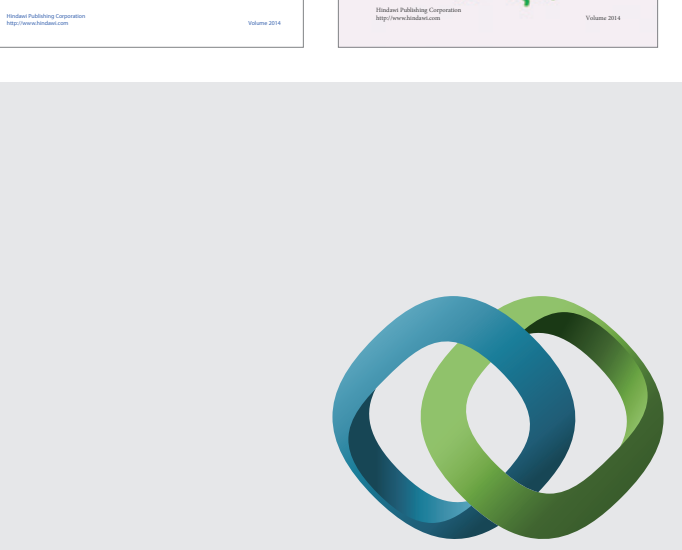

\section{Hindawi}

Submit your manuscripts at

http://www.hindawi.com
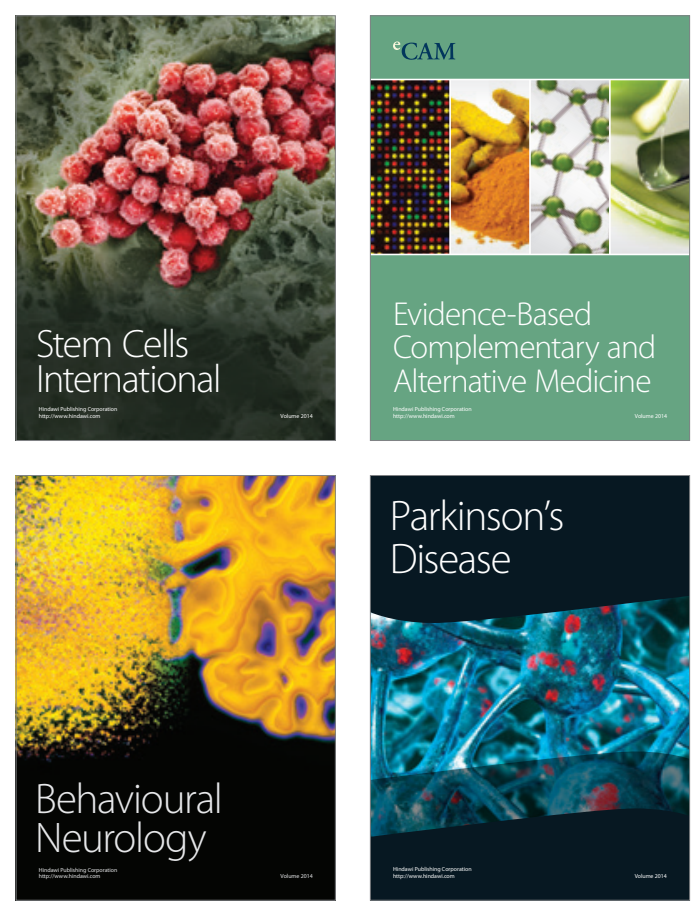

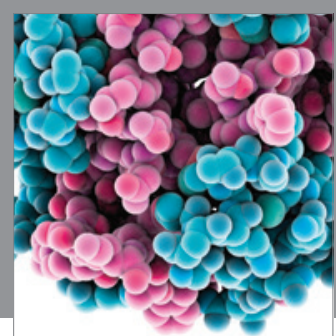

Journal of
Diabetes Research

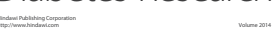

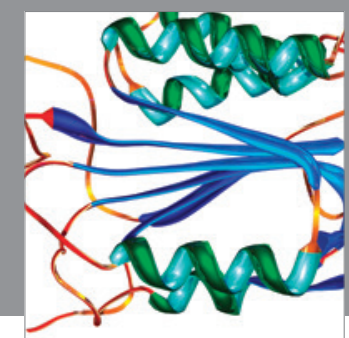

Disease Markers
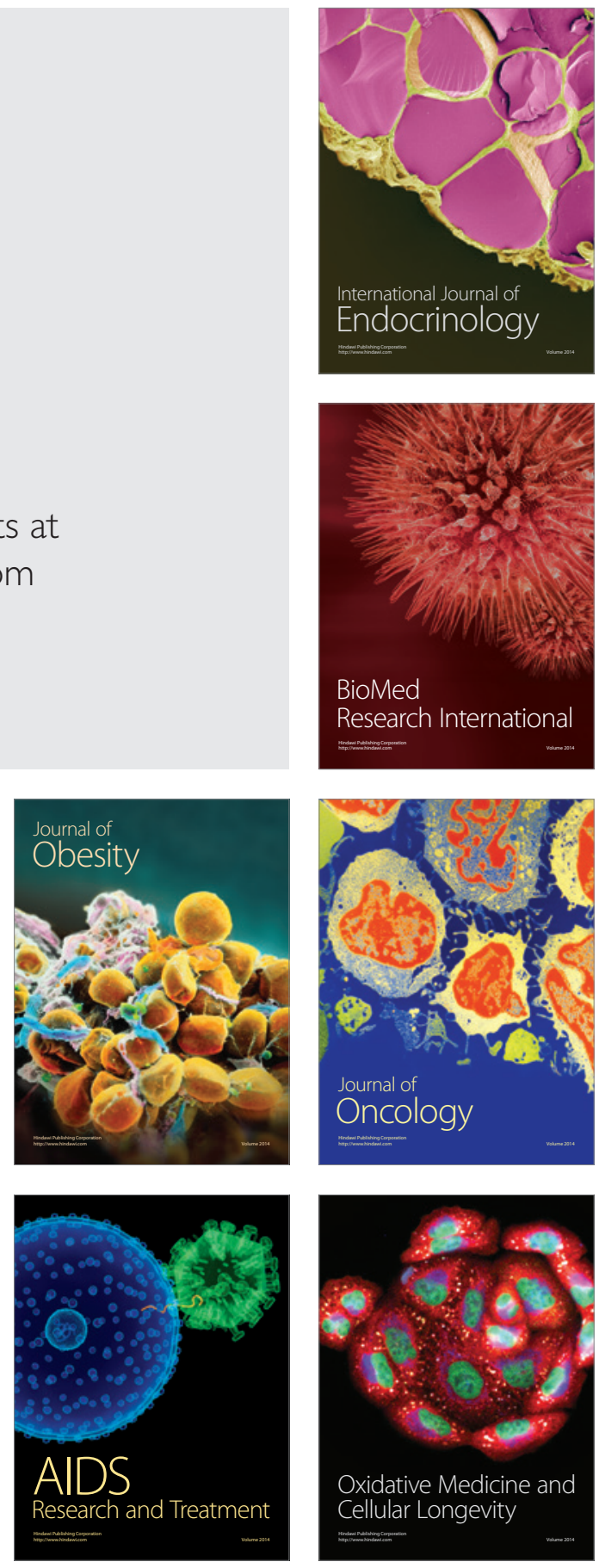